\section{Ethnicity and ocular imaging}

\begin{abstract}
There exist ethnic differences in the prevalence of many ocular diseases. The ocular structures affected by these diseases can be imaged with devices that have increased in complexity over recent years. The purpose of this review is to explore what we mean by the term 'ethnicity' and what we know of ethnic differences in the structures of the eye that are commonly imaged. Finally, the implications of these ethnic differences are discussed in relation to the detection and monitoring of ocular disease that involves imaging instruments. Eye (2011) 25, 297-300; doi:10.1038/eye.2010.187; published online 17 December 2010
\end{abstract}

Keywords: glaucoma; optic disc; imaging

\section{What do we mean by ethnicity?}

The concept of ethnicity is concerned with learned behaviour; the Oxford English dictionary defines 'ethnic' as 'relating to a population subgroup (within a larger or dominant national or cultural group) with a common national or cultural tradition'. It is difficult to define what constitutes race or ethnic group and assignment of individuals to various races/ethnic groups has varied over time and between countries, for example, in the United States, a man with lightly pigmented skin and some African ancestry is labelled black, whereas in Brazil he may be labelled white, and in South Africa he would be labelled coloured. ${ }^{1}$ The concept of race/ethnic groups is not biologically based as human variation is continuous, nonconcordant, and within-group variation is much greater than variation among 'races'. ${ }^{2,3}$ However, self-described race has shown dependent and independent associations in several diseases, such as glaucoma. ${ }^{4}$ In addition, self-described race has shown a high correlation with more sophisticated measures of racial classification that involve genetic admixture techniques and can be considered a surrogate measure. ${ }^{3}$
RRA Bourne $e^{1,2,3,4}$

Why consider ethnicity when imaging the eye?

As described, several ocular diseases have been shown to vary in prevalence by ethnic group/race. For example, age-related macular degeneration (ARMD) is more common in white persons than in persons of African race. ${ }^{5}$ Congdon et $a l^{6}$ reported in 2004 that the leading cause of blindness among white persons older than 40 years in the United States is ARMD (54.4\%), whereas among African persons it accounts for $4.4 \%$ of blindness. From epidemiological studies of primary open-angle glaucoma, African-derived individuals appear to have a higher susceptibility and higher rates of blindness. ${ }^{7,8}$ The following subsections summarise the ethnic differences that have been reported in various ocular structures that are commonly imaged. Understanding of the normal characteristics of these structures and potential variation by ethnicity are important when making judgements of abnormality.

Ethnic differences in ocular structures that are commonly imaged

\section{Cornea}

In several studies, thinner corneas have been observed among African-Americans than in Caucasians. In a clinic-based study, investigators described no significant difference in corneal thickness between Chinese, Caucasian, Filipino, and Hispanic participants, but Japanese participants had significantly thinner corneas, whereas corneas of African-Americans were still thinner. ${ }^{9}$ It has been hypothesized that a thin cornea is a risk factor for glaucoma, aside from the associated intraocular pressure measurement error. ${ }^{10}$ Exploring this assertion, several investigators have however been unable to find a relationship between corneal thickness and retinal nerve fibre layer (RNFL) thickness in healthy or ocular hypertensive eyes by the use of scanning laser polarimetry (SLP), confocal scanning laser ophthalmoscopy (CSLO), and optical coherence tomography (OCT) ${ }^{11,12}$
${ }^{1}$ Vision and Eye Research Unit, Anglia Ruskin University, Cambridge, UK

${ }^{2}$ Hinchingbrooke Hospital NHS Trust, Huntingdon, UK

${ }^{3}$ Moorfields Eye Hospital, London, UK

${ }^{4}$ Addenbrooke's Hospital, Cambridge, UK

Correspondence: RRA Bourne, Department of Ophthalmology, Hinchingbrooke Hospital, Hinchingbrooke Park, Huntingdon, Cambridgeshire PE29 6NT, UK

Tel: + 44 (0)7931 541295;

Fax: + 44 (0)1480 416561

E-mail: rb@rupertbourne.co.uk

Received: 6 September 2010

Accepted in revised form:

1 November 2010

Published online:

17 December 2010

This work will be presented at the Cambridge Ophthalmological Symposium 2010 


\section{Anterior chamber and anterior chamber angle}

Shallow anterior chamber depth and narrow anterior chamber angles are known characteristics of angle closure and angle-closure glaucoma, ${ }^{13}$ both of which are much more commonly found in Chinese ${ }^{14}$ and Inuit populations. ${ }^{15}$ Use of ultrasonic and, more recently, OCT imaging devices has shown the shallowing of anterior chamber that occurs with age; however, findings of recent studies have shown no clearly greater proportion of persons among Chinese individuals with shallower anterior chamber depth compared with European and African populations. ${ }^{16}$ Quigley ${ }^{17}$ and associates have opened an interesting angle of research in this area by showing unfavourable physiological behaviour of the iris in individuals susceptible to angle-closure glaucoma. This is the subject of ongoing longitudinal studies involving OCT imaging in Chinese ${ }^{18}$ and European populations. $^{19}$

\section{Optic nerve head}

Results of stereophotography imaging studies in the 1980s included larger discs, cup/disc ratios, and cup volumes among normal black subjects compared with whites. ${ }^{20}$ These have been followed by many studies involving CSLO, planimetric, and OCT imaging, with confirmation of these ethnic differences in ocular hypertensive patients ${ }^{21}$ and those with glaucoma. ${ }^{22}$ Recent reports from the African Descent and Glaucoma Evaluation Study (ADAGES) study of healthy African- and European-derived participants confirms the larger optic discs, but also smaller rim/disc area ratios in African-derived subjects, when employing OCT, HRT, and SLP instruments. ${ }^{23,24}$ Analyses with the OCT showed no difference between the two ethnic groups following adjustment for age and disc area, nor was there a difference between the groups in respect of the slope of association between age and any structural variable. Average parameter measurements ('typical scan score') with the GDx VCC (SLP with variable corneal compensation) showed a significant difference between ethnic groups following adjustment for disc size and age in both healthy and glaucomatous subjects ${ }^{24}$ in subjects from the ADAGES study.

\section{RNFL, retinal thickness, macular pigment, and retinal vascular calibre}

Investigators from the ADAGES study ${ }^{23}$ reported thicker OCT RNFL measurements in the African-derived healthy individuals in inferior and superior regions at $3.46 \mathrm{~mm}$ from the centre of the disc following adjustment for differences in optic disc area and age. Conversely, the
RNFL thickness in the temporal region (the papillomacular bundle) was significantly thinner in the African-derived group. The OCT also showed no difference between ethnic groups with optic nerve head variables after adjusting for age and disc area. Kelty et $a l^{25}$ reported greater mean foveal thickness in Caucasians than African-Americans, with the Stratus OCT in 83 healthy subjects. Kashani et $a l^{26}$ also reported decreased mean foveal thickness and centre point thickness in African-Americans compared with Caucasians and Hispanics in a university-based study using Stratus OCT.

Imaging of macular pigment using autofluorescence images from confocal laser scanning ophthalmoscopy has been used to show higher central macular pigment density higher in Africans. There is evidence to suggest that macular pigment protects against age-related maculopathy and ARMD by filtering blue light, although this is controversial. ${ }^{27}$ Improved genotype-phenotype correlation may be obtained for these and other retinal diseases with the advent of modern OCT devices that use ultra-high resolution to image the photoreceptor layer and Bruch's membrane thickness.

The findings of the Multi-Ethnic Study of Atherosclerosis ${ }^{28-30}$ have indicated that changes in vascular calibre (measured with fundus photography) may predict a range of cardiovascular diseases, independent of established risk factors. Investigators from this study reported larger retinal arteriolar and venular calibres in blacks and Hispanics than whites and Chinese, which may be of use in establishing risk of cardiovascular disease by ethnic group. However, more recent reports have suggested that these reported ethnic differences may be a result of a measurement error where darkly pigmented eyes have less contrast between the vessel edge and the surrounding retina than less pigmented eyes. ${ }^{31}$

\section{Implications of ethnic differences of ocular structure for diagnostic imaging}

Several imaging techniques evaluate ocular structures to discriminate between normal and abnormal states of health. This is particularly the case in glaucoma detection where CSLO, SLP, and OCT instruments are commonly used to evaluate optic disc topography and the peripapillary retinal nerve fibre layer. Early detection of change to these structures is important as visual field defects may only develop after a large proportion of retinal ganglion cells have been damaged. ${ }^{32,33}$ A good example of the issues surrounding ethnic differences is described as follows with the Heidelberg Retina Tomograph (confocal scanning laser ophthalmoscope), which uses a software analysis program named 
Moorfields Regression Analysis (MRA) to compare the subject's optic nerve and RNFL parameters to a normative database.

The normative database for the HRT originally comprised 112 white (72 healthy; 51 with early glaucoma) subjects, all of whom were white and had ametropia of less than 16 dioptres. ${ }^{34}$ The MRA utilizes global and regional rim sectors area estimates adjusted for optic disc size and age in an effort to improve specificity. The adjustment for disc area, which accounts for most of the differences between racial groups, is important; however, studies with larger and more ethnically diverse clinic-based studies have found the MRC classification to perform less well at diagnosing glaucoma in eyes with large optic discs. ${ }^{35}$ Use of the MRA in a population-based setting ${ }^{36}$ found the MRA to be of limited value for population screening for glaucoma with lower sensitivities and specificities than previous clinic-based studies. This is because the normative database did not account adequately for variation in optic disc size in this population, but is also likely to be owing to the variation in accuracy of HRT algorithms known to occur with different study designs. ${ }^{37}$ The effect of the additional normative data from other ethnic groups (Indian and African-American) into the HRT software of the latest version, the HRT III, ${ }^{38}$ on the ability to discriminate glaucomatous and non-glaucomatous eyes, has been studied. In one study, sensitivity of the MRA algorithm was improved with the larger more ethnically diverse normative database in African subjects, yet at the expense of specificity. ${ }^{39}$

\section{Conclusions}

This review has highlighted some of the issues surrounding the definition of ethnic group/race and the reliance of many studies on self-report. However, many ocular diseases are known to vary in prevalence and phenotype with self-reported ethnicity, and indeed structures of the eye that are commonly imaged also vary with ethnicity. Ethnic-specific normative databases incorporated into the software of imaging instruments appear to be of benefit when accounting for the variation between different populations, but the design of the studies that collect these data are an important consideration. For example, clinic-derived databases may be inappropriate when imaging at a population level (eg, 'screening'). There has been much progress in the development of ocular imaging instruments, with improved resolution of ocular structures. Often this means that the output of more recent instruments cannot be directly compared with that of previous models ('backwards compatability'), ${ }^{40}$ with the result that 'normative data' collected by the older version becomes obsolete. Although there are many difficulties associated with judging normalcy of ocular structures at the diagnostic stage, the real benefit of several of these instruments would appear to lie in the detection of temporal change within a given individual. However, little is known of the role that ethnicity plays in the temporal change of ocular structures in normal and disease states.

\section{Conflict of interest}

The author declares no conflict of interest.

\section{References}

1 Wilson MR. What is race? Int Ophthalmol Clin 2003; 43(4): $1-8$.

2 Goodman AH. Why genes don't count (for racial differences in health). Am J Public Health 2000; 90(11): 1699-1702.

3 Rosenberg NA, Pritchard JK, Weber JL, Cann HM, Kidd KK, Zhivotovsky LA et al. Genetic structure of human populations. Science 2002; 298(5602): 2381-2385.

4 Tielsch JM, Sommer A, Katz J, Royall RM, Quigley HA, Javitt J. Racial variations in the prevalence of primary openangle glaucoma. The Baltimore Eye Survey. JAMA 1991; 266(3): 369-374.

5 Sommer A, Tielsch JM, Katz J, Quigley HA, Gottsch JD, Javitt JC et al. Racial differences in the cause-specific prevalence of blindness in east Baltimore. N Engl J Med 1991; 325: 1412-1417.

6 Congdon N, O'Colmain B, Klaver CC, Klein R, Muñoz B, Friedman DS et al. Causes and prevalence of visual impairment among adults in the United States. Arch Ophthalmol 2004; 122: 477-485.

7 Muñoz B, West SK, Rubin GS, Schein OD, Quigley HA, Bressler SB et al. Causes of blindness and visual impairment in a population of older Americans: the Salisbury Eye Evaluation Study. Arch Ophthalmol 2000; 118(6): 819-825.

8 Sommer A. Glaucoma risk factors observed in the Baltimore Eye Survey. Curr Opin Ophthalmol 1996; 7(2): 93-98.

9 Aghaian E, Choe JE, Lin S, Stamper RL. Central corneal thickness of Caucasians, Chinese, Hispanics, Filipinos, African Americans, and Japanese in a glaucoma clinic. Ophthalmology 2004; 111(12): 2211-2219.

10 Medeiros FA, Sample PA, Zangwill LM, Bowd C, Aihara M, Weinreb R. Corneal thickness as a risk factor for visual field loss in patients with preperimetric glaucomatous optic neuropathy. Am J Ophthalmol 2003; 136(5): 805-813.

11 Henderson PA, Medeiros FA, Zangwill LM, Weinreb RN. Relationship between central corneal thickness and retinal nerve fiber layer thickness in ocular hypertensive patients. Ophthalmology 2005; 112: 251-256.

12 Mumcuoglu T, Townsend KA, Wollstein G, Ishikawa H, Bilonick RA, Sung KR et al. Advanced Imaging in Glaucoma Study Group. Assessing the relationship between central corneal thickness and retinal nerve fiber layer thickness in healthy subjects. Am J Ophthalmol 2008; 146(4): 561-566.

13 Alsbirk PH. Primary angle-closure glaucoma: oculometry, epidemiology, and genetics in a high risk population. Acta Ophthalmol 1976; 54: 5-31. 
14 Foster PJ, Johnson GJ. Glaucoma in China: how big is the problem? Br J Ophthalmol 2001; 85(11): 1277-1282.

15 Bourne RR, Sørensen KE, Klauber A, Foster PJ, Johnson GJ, Alsbirk PH. Glaucoma in East Greenlandic Inuit-a population survey in Ittoqqortoormiit (Scoresbysund). Acta Ophthalmol Scand 2001; 79(5): 462-467.

16 Congdon NG, Youlin Q, Quigley H, Hung PT, Wang TH, Ho TC et al. Biometry and primary angle-closure glaucoma among Chinese, White, and Black populations. Ophthalmology 1997; 104: 1489-1495.

17 Quigley HA. Angle-closure glaucoma-simpler answers to complex mechanisms: LXVI Edward Jackson Memorial Lecture. Am J Ophthalmol 2009; 148(5): 657-669.

18 Yuen LH, He M, Aung T, Htoon HM, Tan DT, Mehta JS. Biometry of the cornea and anterior chamber in Chinese eyes: an anterior segment optical coherence tomography study. Invest Ophthalmol Vis Sci 2010; 51(7): 3433-3440.

19 Bourne RRA, Chang L, Sanchez Parra L, Buckley R, Pardhan S. Investigating Management of Primary Angle Closure and Treatment Study - the IMPACT study. https://portal.nihr.ac.uk/Pages/Portfolio.aspx. (accessed 30 August 2010).

20 Chi T, Ritch R, Stickler D, Pitman B, Tsai C, Hsieh FY. Racial differences in optic nerve head parameters. Arch Ophthalmol 1989; 107(6): 836-839.

21 Zangwill LM, Weinreb RN, Berry CC, Smith AR, Dirkes KA, Coleman AL et al. Kass MA Racial differences in optic disc topography: baseline results from the confocal scanning laser ophthalmoscopy ancillary study to the ocular hypertension treatment study. Arch Ophthalmol 2004; 122(1): 22-28.

22 Girkin CA, McGwin Jr G, Long C, DeLeon-Ortega J, Graf CM, Everett AW. Subjective and objective optic nerve assessment in African Americans and whites. Invest Ophthalmol Vis Sci 2004; 45: 2272-2278.

23 Girkin CA, Sample PA, Liebmann JM, Jain S, Bowd C, Becerra LM et al. ADAGES Group. African Descent and Glaucoma Evaluation Study (ADAGES): II. Ancestry differences in optic disc, retinal nerve fiber layer, and macular structure in healthy subjects. Arch Ophthalmol 2010; 128(5): 541-550.

24 Sassani PP, Sample PA, Vizzeri G, Nguyen B, Weinreb RN, Medeiros $\mathrm{F}$ et al. The influence of race on the detection of glaucoma using scanning laser polarimetry with variable corneal compensation in the African Descent and Glaucoma Evaluation Study (ADAGES) and Diagnostic Innovations in Glaucoma Study (DIGS). Invest Ophthalmol Vis Sci 2010; 51: e-abstract 2731.

25 Kelty PJ, Payne JF, Trivedi RH, Kelty J, Bowie EM, Burger B. Macular thickness assessment in healthy eyes based on ethnicity using Stratus OCT optical coherence tomography. Invest Ophthalmol Vis Sci 2008; 49(6): 2668-2672.

26 Kashani AH, Zimmer-Galler IE, Shah SM, Dustin L, Do DV, Eliott $\mathrm{D}$ et al. Retinal thickness analysis by race, gender, and age using Stratus OCT. Am J Ophthalmol 2010; 149(3): 496-502.

27 Mares-Perlman JA, Brady WE, Klein R, Vanden Langenberg GM, Klein BE, Palta M. Dietary fat and age-related maculopathy. Arch Ophthalmol 1995; 113: 743-748.
28 Wong TY, Klein R, Klein BE, Tielsch JM, Hubbard L, Nieto FJ. Retinal microvascular abnormalities, and their relation to hypertension, cardiovascular diseases and mortality. Surv Ophthalmol 2001; 46: 59-80.

29 Wong TY, Mitchell P. Hypertensive retinopathy. N Engl J Med 2004; 351: 2310-2317.

30 Wong TY, Islam FM, Klein R, Klein BE, Cotch MF, Castro C et al. Retinal vascular caliber, cardiovascular risk factors, and inflammation: the multi-ethnic study of atherosclerosis (MESA). Invest Ophthalmol Vis Sci 2006; 47(6): 2341-2350.

31 Rochtchina E, Wang JJ, Taylor B, Wong TY, Mitchell P. Ethnic variability in retinal vessel caliber: a potential source of measurement error from ocular pigmentation? - the Sydney Childhood Eye Study. Invest Ophthalmol Vis Sci 2008; 49(4): 1362-1366.

32 Quigley HA, Katz J, Derick RJ, Gilbert D, Sommer A. An evaluation of optic disc and nerve fiber layer examinations in monitoring progression of early glaucoma damage. Ophthalmology 1992; 99: 19-28.

33 Harwerth RS, Carter-Dawson L, Shen F, Smith III EL, Crawford ML. Ganglion cell losses underlying visual field defects from experimental glaucoma. Invest Ophthalmol Vis Sci 1999; 40: 2242-2250.

34 Garway-Heath DG. Moorfields regression analysis. In: Fingeret M, Flanagan JG, Liebmann JM (eds). The Essential HRT Primer. Jocoto Advertising Inc.: San Ramon, CA, 2005, pp 31-39.

35 Girkin CA, DeLeon-Ortega JE, Xie A, McGwin G, Arthur SN, Monheit BE. Comparison of the Moorfields classification using confocal scanning laser ophthalmoscopy and subjective optic disc classification in detecting glaucoma in blacks and whites. Ophthalmology 2006; 113(12): 2144-2149.

36 Zheng Y, Wong TY, Lamoureux E, Mitchell P, Loon SC, Saw SM et al. Diagnostic ability of Heidelberg Retina Tomography in detecting glaucoma in a population setting: the Singapore Malay Eye Study. Ophthalmology 2010; 117(2): 290-297.

37 Medeiros FA, Ng D, Zangwill LM, Sample PA, Bowd C, Weinreb RN. The effects of study design and spectrum bias on the evaluation of diagnostic accuracy of confocal scanning laser ophthalmoscopy in glaucoma. Invest Ophthalmol Vis Sci 2007; 48: 214-222.

38 Sinai MJ, Girkin CA, Garway-Heath D, Thomas R, Scheuerle A, Volz D et al. Ethnic differences in healthy eyes with the HRT 3 Invest Ophthalmol Vis Sci 2006; 47: e-abstract 4350.

39 De León-Ortega JE, Sakata LM, Monheit BE, McGwin Jr G, Arthur SN, Girkin CA. Comparison of diagnostic accuracy of Heidelberg Retina II Tomograph and Heidelberg Retina Tomograph 3 to discriminate glaucomatous and nonglaucomatous eyes. Am J Ophthalmol 2007; 144(4): 525-532.

40 Bourne RR, Medeiros FA, Bowd C, Jahanbakhsh K, Zangwill LM, Weinreb RN. Comparability of retinal nerve fiber layer thickness measurements of optical coherence tomography instruments. Invest Ophthalmol Vis Sci 2005; 46(4): 1280-1285. 